\section{Relative Bradycardia in Patients with Mild-to- Moderate Coronavirus Disease, Japan}

\author{
Kazuhiko Ikeuchi, Makoto Saito, Shinya Yamamoto, \\ Hiroyuki Nagai, Eisuke Adachi
}

Author affilation: The University of Tokyo, Tokyo, Japan

DOI: https://doi.org/10.3201/eid2610.202648

Coronavirus disease is reported to affect the cardiovascular system. We showed that relative bradycardia was a common characteristic for 54 patients with PCRconfirmed mild-to-moderate coronavirus disease in Japan. This clinical sign could help clinicians to diagnose this disease.

Dulse rate usually increases 18 beats/min for each $11^{\circ} \mathrm{C}$ increase in body temperature (1). However, in some specific infectious diseases, pulse rate does not increase as expected, a condition called relative bradycardia. High fever (temperature $>39^{\circ} \mathrm{C}$ ) for patients with coronavirus disease (COVID-19) has been reported $(2,3)$, but the association between fever and pulse rate has not been investigated. We investigated relative bradycardia as a characteristic clinical feature in patients with mild-to-moderate COVID-19.

Retrospective analyses of routinely collected clinical records of COVID-19 patients were approved by the ethics committee of the Institute of Medical Science, The University of Tokyo (approval no. 2020-5-0420). During March 1-May 14, we identified all adult hospitalized patients with COVID-19 at a university hospital in Tokyo, Japan. We confirmed diagnoses of COVID-19 by using reverse transcription PCR. Patients who had known factors that could affect pulse rate (e.g., concurrent conditions or medications) were excluded.

We obtained the highest body temperature in each day during hospitalization and the pulse rate at the time. To account for within-person correlation, we used 2-level mixed-effects linear regression (with random intercept) for analysis of factors associated with pulse rate: age, sex, time from first symptoms, systolic blood pressure, diastolic blood pressure, respiratory rate, and percutaneous oxygen saturation.

We performed variable selection by backward elimination using a $\mathrm{p}$ value of 0.05 by likelihood ratio test as the cutoff value. We performed statistical analysis by using Stata MP 15.1 (StataCorp, https:/ / www.stata.com). Relative bradycardia was defined as an increase in pulse rate $<18$ beats/min for each $1^{\circ} \mathrm{C}$ increase in body temperature (1).

During the study period, 57 patients with COVID-19 were admitted to our hospital (Table); 3 patients were excluded ( 2 were receiving beta-blockers and 1 had a pulmonary embolism). The median age was 45.5 years (range $20-81$ years), and $72.2 \%$ $(39 / 54)$ of patients were male. Median time from the appearance of first symptoms to admission was 9 days (range 2-25 days). At admission, median body temperature was $37.2^{\circ} \mathrm{C}$ (range $36.1^{\circ} \mathrm{C}-39.2^{\circ} \mathrm{C}$ ), pulse rate 84 beats/min (range $62-134$ beats/min), and systolic blood pressure, $116 \mathrm{~mm} \mathrm{Hg}$ (range 80-170 mm Hg). During admission, $13.0 \%(7 / 54)$ of patients had high fever (temperature $>38.9^{\circ} \mathrm{C}$ ), and all had a pulse rate $<120$ beats/min (range $72-114$ beats/min).

We performed computed tomography and electrocardiography for all patients: no patients were given a diagnosis of cardiac disease. Computed tomography showed pneumonia for 49 (90.7\%) patients, and 11 (20.4\%) patients required oxygen therapy without intubation. A total of 24 patients received COVID-19-specific treatment (favipiravir, $\mathrm{n}=15$; hydroxychloroquine, $\mathrm{n}=10$; both drugs, $\mathrm{n}$ $=1$ ); no patients received vasopressors, or corticosteroids for COVID-19. All patients improved and were discharged.

Body temperature, respiratory rate, systolic blood pressure, and time after the first symptoms (in days) were associated with pulse rate by univariable analysis (Appendix Table, https:/ / wwwnc.cdc. gov/EID/article/26/10/20-2648-App1.pdf). However, only body temperature was independently associated with pulse rate by multivariable analysis. The predicted change in pulse rate was 7.37 (95\% CI $5.92-8.82$ ) beats/ $\mathrm{min}$ for each $1^{\circ} \mathrm{C}$ increase in body temperature (Figure).

Relative bradycardia is a characteristic physical finding in some intracellular bacterial infections, viral infections, and noninfectious diseases (4). Our data showed that a predicted change in pulse rate was $<18$ beats $/ \mathrm{min}$ for each $1^{\circ} \mathrm{C}$ increase in patients with COVID-19. Furthermore, all patients with high fever also met another criterion of relative bradycardia (i.e., body temperature $>38.9^{\circ} \mathrm{C}$ with pulse rate $<120$ beats/ $\mathrm{min}$ ) (1).

Although the mechanism of relative bradycardia is not known, a hypothesis is that increased levels of inflammatory cytokines, such as interleukin-6, which was reported for patients with COVID-19, can increase vagal tone and decrease heart rate variability (4-6). 
Table. Characteristics of patients with relative bradycardia and mild-to-moderate coronavirus disease, Japan

\begin{tabular}{|c|c|c|}
\hline Characteristic & No. assessed & Value $^{*}$ \\
\hline Age, y & 54 & $45.5(20-81)$ \\
\hline \multicolumn{3}{|l|}{ Sex } \\
\hline M & 39 & $39(72.2)$ \\
\hline $\mathrm{F}$ & 15 & $15(27.8)$ \\
\hline Body mass index, $\mathrm{kg} / \mathrm{m}^{2}$ & 54 & $23.7(15.9-51.1)$ \\
\hline Current smoker & 48 & $16(33.3)$ \\
\hline Days from symptom onset to admission & 54 & $9(2-25)$ \\
\hline \multicolumn{3}{|l|}{ Vital signs at admission } \\
\hline Body temperature, ${ }^{\circ} \mathrm{C}$ & 54 & $37.2(36.1-39.2)$ \\
\hline Pulse rate, beats $/ \mathrm{min}$ & 54 & $84(62-134)$ \\
\hline Systolic blood pressure, $\mathrm{mm} \mathrm{Hg}$ & 54 & $116(80-170)$ \\
\hline Diastolic blood pressure, $\mathrm{mm} \mathrm{Hg}$ & 54 & $70.5(51-124)$ \\
\hline Respiratory rate, breaths/min & 53 & $18(16-26)$ \\
\hline Percutaneous oxygen saturation, \%† & 54 & $97(92-100)$ \\
\hline Highest temperature during admission, ${ }^{\circ} \mathrm{C}$ & 54 & \\
\hline$<37.5$ & 54 & $27(50.0)$ \\
\hline $37.5-38.9$ & 54 & $20(37.0)$ \\
\hline$>38.9^{\circ} \mathrm{C}$ & 54 & $7(13.0)$ \\
\hline \multicolumn{3}{|l|}{ Laboratory findings at admission } \\
\hline Leukocyte count, cells $/ \mathrm{mm}^{3}$ & 54 & $5,530(2,690-16,700)$ \\
\hline Lymphocyte count, cells $/ \mathrm{mm}^{3}$ & 54 & $1,251(381-2,852)$ \\
\hline Hemoglobin, g/dL & 54 & $14.7(11.1-17.3)$ \\
\hline Platelet count, $\times 1,000 / \mathrm{mm}^{3}$ & 54 & $231(106-444)$ \\
\hline Blood urea nitrogen, $\mathrm{mmol} / \mathrm{L}$ & 54 & $4.3(2.1-7.9)$ \\
\hline Creatinine, $\mu \mathrm{mol} / \mathrm{L}$ & 54 & $69.0(34.5-120.2)$ \\
\hline Sodium, $\mathrm{mmol} / \mathrm{L}$ & 53 & $139(132-148)$ \\
\hline Potassium, mmol/L & 53 & $4.0(3.1-4.8)$ \\
\hline Creatine kinase, U/L & 52 & $74(22-674)$ \\
\hline C-reactive protein, $\mathrm{mg} / \mathrm{L}$ & 54 & $17.9(0.1-215.6)$ \\
\hline Brain natriuretic peptide, $\mathrm{pg} / \mathrm{mL}$ & 52 & $5.8(5.8-43.2)$ \\
\hline $\mathrm{D}$-dimer, $\mathrm{mg} / \mathrm{L}$ & 50 & $0.5(0.5-6.5)$ \\
\hline \multicolumn{3}{|l|}{ Concurrent conditions } \\
\hline Hypertension & 54 & $8(14.8)$ \\
\hline Diabetes & 54 & $5(9.3)$ \\
\hline Chronic obstructive pulmonary disease & 54 & $1(1.9)$ \\
\hline Coronary heart disease & 54 & $0(0)$ \\
\hline HIV Infection & 54 & $4(7.4)$ \\
\hline
\end{tabular}

Another hypothesis is that the toxic effect on the nervous system caused by SARS-CoV-2 (7) disturbs autonomic control of heart rate. Angiotensin-converting enzyme 2, which is the receptor for SARS-CoV-2, is

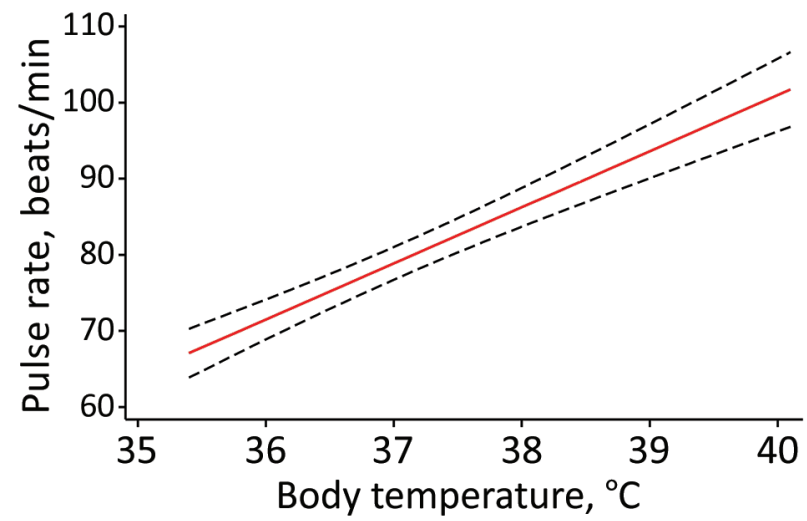

Figure. Predicted pulse rate over body temperature (red line) based on final random intercept model for relative bradycardia in patients with mild-to-moderate coronavirus disease, Japan. Black dashed lines indicate $95 \%$ Cls. known to be expressed on cardiac cells (8). Therefore, relative bradycardia might reflect a characteristic inflammatory response to COVID-19, directly or indirectly affecting cardiovascular system.

There are several limitations in our study. First, 34 patients received antipyretic medicines during their hospitalization (acetaminophen, $\mathrm{n}=33$; loxoprofen, $\mathrm{n}=1$ ), and 1 patient received prednisolone (5 mg/day) for myasthenia gravis. Because fever was underestimated for patients who received these medications, relative bradycardia might be a more common clinical sign. In our cohort, body temperature decreased over time. Although there was a relationship between pulse rate and time after first symptom in a univariable model, this finding was probably confounded by body temperature and thus not significant when adjusted. Second, our data did not include patients who were intubated. Additional research on patients with severe respiratory dysfunction is needed. 
In summary, relative bradycardia was a characteristic clinical finding in patients who had mild-tomoderate COVID-19 in Japan. This clinical sign could help clinicians diagnose COVID-19.

\section{About the Author}

Dr. Ikeuchi is a graduate student at the Institute of Medical Science, University of Tokyo, Tokyo, Japan. His primary research interest is HIV.

\section{References}

1. Cunha BA. The diagnostic significance of relative bradycardia in infectious disease. Clin Microbiol Infect. 2000; 6:633-4. https:// doi.org/10.1046/j.1469-0691.2000.0194f.x

2. Guan WJ, Ni ZY, Hu Y, Liang WH, Ou CQ, He JX, et al.; China Medical Treatment Expert Group for Covid-19. Clinical characteristics of coronavirus disease 2019 in China. N Engl J Med. 2020;382:1708-20. https:/ / doi.org/10.1056/ NEJMoa2002032

3. Lian J, Jin X, Hao S, Cai H, Zhang S, Zheng L, et al. Analysis of epidemiological and clinical features in older patients with corona virus disease 2019 (COVID-19) out of Wuhan. Clin Infect Dis. 2020;Mar 25:ciaa242. https:/ / doi.org/10.1093/ $\mathrm{cid} / \mathrm{ciaa} 242$

4. Ye F, Hatahet M, Youniss MA, Toklu HZ, Mazza JJ, Yale $S$. The clinical significance of relative bradycardia. WMJ. 2018;117:73-8.

5. Ye F, Winchester D, Stalvey C, Jansen M, Lee A, Khuddus M, et al. Proposed mechanisms of relative bradycardia. Med Hypotheses. 2018;119:63-7. https:/ / doi.org/10.1016/ j.mehy.2018.07.014

6. Hajiasgharzadeh K, Mirnajafi-Zadeh J, Mani AR. Interleukin-6 impairs chronotropic responsiveness to cholinergic stimulation and decreases heart rate variability in mice. Eur J Pharmacol. 2011;673:70-7. https:/ / doi.org/ 10.1016/j.ejphar.2011.10.013

7. Mao L, Jin H, Wang M, Hu Y, Chen S, He Q, et al. Neurologic manifestations of hospitalized patients with coronavirus disease 2019 in Wuhan, China. JAMA Neurol. 2020;77:68390. https:// doi.org/10.1001/jamaneurol.2020.1127

8. Li W, Moore MJ, Vasilieva N, Sui J, Wong SK, Berne MA, et al. Angiotensin-converting enzyme 2 is a functional receptor for the SARS coronavirus. Nature. 2003;426:450-4. https://doi.org/10.1038/nature02145

Address for correspondence: Eisuke Adachi, Department of Infectious Diseases and Applied Immunology, Institute of Medical Science, The University of Tokyo, 4-6-1 Shirokanedai, Minato-ku, Tokyo, Japan; email: eadachi-ims@umin.ac.jp

\section{Effect of COVID-19 on Tuberculosis Notification, South Korea}

\author{
Nakwon Kwak, Seung-Sik Hwang, Jae-Joon Yim \\ Author affiliations: Seoul National University College of Medicine, \\ Seoul, South Korea (N. Kwak, J.-J. Yim); Seoul National \\ University Graduate School of Public Health, Seoul (S.-S. Hwang)
}

DOI: https://doi.org/10.3201/eid2610.20-2782

After South Korea raised its infectious disease alert to the highest level in response to coronavirus disease emergence, tuberculosis notification during the first 18 weeks of 2020 decreased significantly from the same period for each year during 2015-2019. Adequate measures to diagnose, control, and prevent tuberculosis need to be maintained.

Ts he first case of coronavirus disease (COVID-19) in South Korea was identified on January 20, 2020, and an outbreak from a church hastened widespread transmission throughout the country (1). On February 23, the government of South Korea raised the country's infectious disease alert to the highest level and initiated vigorous infection control measures: establishing widespread diagnostic capacity, initiating local contact tracing, mandating physical distancing, and redesigning triage and treatment systems (2). While this alert level remains in effect, such measures could negatively affect other communicable diseases, such as tuberculosis (TB) (3). To investigate the effect of COVID-19 on TB diagnoses, we traced the number of notified TB cases in South Korea before and after the COVID-19 outbreak started and compared them with previous years, during which the burden of TB has been at an intermediate level.

We gathered the weekly number of newly notified TB cases for 2015-2020 from the Public Health Weekly Report released by the Korea Centers for Disease Control and Prevention. In South Korea, physicians and healthcare workers are required to report confirmed or clinically diagnosed TB to health authorities within 24 hours, irrespective of any previous history of TB treatment (4). The Public Health Weekly Report publishes the number of notified TB cases by province every week (1). In addition, the number of confirmed COVID-19 cases is posted daily on the Korea Centers for Disease Control and Prevention website (1).

We calculated the mean number of weekly TB notifications from the 1st through the 18th week of each year from 2015 through 2019. We also collected the 